\title{
Diagnose Urban Drainage Network Problem Based on Internet of Things and Big Data
}

\author{
Xiaobo Miao ${ }^{1}$, Mou Lv ${ }^{1, a}$, Fengchao Liang ${ }^{1}$, Chunjiao Jiao ${ }^{1}$ and Luohua Wang ${ }^{1}$ \\ ${ }^{1}$ School of Environment and Municipal Engineering, Qingdao University of Technology, 266033 Qingdao, China
}

\begin{abstract}
Urban drainage pipe network is an important foundation project in urban construction. It has a vital impact on urban waterlogging prevention and water pollution. However, in the current practice, there are many hidden problems in the pipe network, and it is difficult to check the pipe network problem, which restricts the understanding of the drainage system problem to a certain extent. In order to solve the two technical problems of drainage network survey and data statistics, the monitoring technology based on Internet of things and big data is adopted in this study. Taking the sponge city pilot area of a coastal city in China as the research area, the monitoring scheme was established and the monitoring data were obtained. Based on more than 6 million monitoring data, the automatic analysis algorithm is applied to analyse the problems of mixed connection of rain and sewage and tidal backwater in the pipeline network. The results show that there are a total of 17 outlets in 160 outlets with problems of rain and sewage mixing. Among them, there are four outlets with regular domestic sewage entering the rainwater pipe network, 7 outlets with irregular sewage entering the rainwater pipe network, and 6 outlets where sewage is smuggled into the rainwater pipe network. In addition, there is a sea tidal backwater phenomenon at one of the coastal rainwater outfalls.
\end{abstract}

\section{Introduction}

The drainage network has many defects, such as concealment, complexity, uncertainty, unreasonable design, pipe network mixing, and stealthy drainage and so on. The traditional drainage management decision is mainly based on empirical judgment, and it is difficult to systematically evaluate the operation performance of the drainage network. Drainage pipe network monitoring is of great significance for urban storm water management. Strengthening pipe network monitoring helps to protect drainage facilities, improve drainage system, and urban information management [1], which is the basis for the construction of information platform. The performance of drainage network is evaluated by on-line monitoring technology to guide the operation management and maintenance design of drainage system. This has been developed and widely used in Europe and the United States [2].

There have been many researches on hydraulic and water quality monitoring of pipe network at home and abroad. Jonathan W. Berry et al. optimized the location of sensors in municipal networks to detect maliciously injected contaminants [3]. M. Jiménez-Buendía et al. evaluated the water balance by developing new SCADA monitoring software and equipment to reduce costs [4]. M. Moy de Vitry et al. used traditional and alternative sensors to monitor urban flash flooding experiments, providing both traditional measurement and video data [5]. Yuanming Guo, Chase Holton et al. Andi studied on the determination of alternative steam intrusion into sewers by gas monitoring and screening calculation [6]. With the development of information technology, there are some researches on the problem of detecting and repairing pipeline by intelligent robot [7-8].

Through the online monitoring information platform of the drainage pipe network, the pilot area of the sponge city in a certain city of China is taken as the research area. According to the online monitoring operation data, based on the monitoring technology of the Internet of Things and big data and the automatic analysis algorithm, the operation status of the drainage network is evaluated, and the problems such as rain and sewage mixing, sewage smuggling, and tidal top support are diagnosed. It helps to provide decision-making basis for pipe network management and maintenance.

\section{Internet of Things Platform}

\subsection{Drainage Internet of Things Monitoring System}

The overall design of the system is to adopt the $\mathrm{B} / \mathrm{S}$ and $\mathrm{M} / \mathrm{S}$ hybrid system architecture, and the construction data can be uploaded through the web and mobile terminals. The drainage Internet of Things monitoring system can realize the inquiry and analysis of the comprehensive information related to the urban drainage pipe network, which can facilitate the managers to

\footnotetext{
a Corresponding author: Lvmou1@163.com
} 
quickly and efficiently obtain the required information, and grasp the operation status of the complex system of the entire drainage pipe network from a macro perspective. Real-time monitoring of important indicators of key facilities for transporting sewage capacity in urban drainage network system overcomes the shortcomings of conventional drainage network business activities that are difficult to find potential dysfunction of the system. Comprehensive management of monitoring equipment can detect liquid level variation of the monitoring wells timely. In this way, the normal liquid level, early warning, alarm and overflow can be effectively identified. Real-time control of monitoring data and real-time diagnosis of the operation of the drainage network can provide a strong guarantee for the safe operation of the pipeline network.

\subsection{Automatic analysis algorithm}

A total of 329 sets of equipment were installed in the pilot area, of which 160 flow meters were used for port, project, facility and pipe network monitoring. The equipment was in good condition and a total of 6912000 valid data were obtained. Due to the large amount of data, an automatic analysis algorithm is used. The automatic analysis algorithm is based on MATLAB, which can be used to realize the statistical analysis of the monitoring data. By setting the minimum daily cumulative flow and the minimum monitoring liquid level judgment standard, we can analyse the equipment monitoring flow and liquid level, and counts the equipment that is larger than this standard without the rainfall. In the dry season of rainwater pipe network, the number of equipment for sewage or infiltration water inflow can be automatically extracted. The data of the pipe network is connected to the minute level.

\section{Overview of research regions and monitoring}

\subsection{Overview of research regions}

The study area is 25.32 square kilometres. The main water system in the area is Lou Shan River, Banqiao Fang River and Dacun River. Sponge city is constructed in the region, which contains a total of 182 projects. Project types include road and square projects, park green space construction, buildings and residential areas, and so on. The pipe network in the test area is separated by rain and sewage.

\subsection{On-line monitoring instrument}

The Flowmeter adopts the velocity area method. The velocity measurement uses the Doppler ultrasonic measurement principle. Meanwhile, the liquid level measurement uses the pressure or the ultrasonic wave measurement principle. In this way, the velocity and the liquid level can be simultaneously recorded using the continuous measurement respectively. The measuring frequency is set to be $1 \mathrm{~min}$. The on-line flow rate of each catchment area is monitored 24 hours on line, and 1440 data can be obtained stably per day for each equipment.

\subsection{Equipment layout}

In combination with the pilot construction and monitoring scheme of sponge city, on-line monitoring equipment has been installed, including typical projects and facilities monitoring, river channel and waterlogging point liquid level monitoring, river channel SS on-line water quality monitoring, and main drainage discharge monitoring. A total of 160 Flowmeters have been installed, which is mainly distributed in the drainage zone outlet, the key node of the rainwater pipe network inspection well, the water outlet of the important land block, the typical project outlet and the source facility outlet. The installation at the outlet of the drainage zone provides the basis for the calculation of the total annual runoff control rate in the drainage zone and the placement of the key nodes in the municipal drainage network provides the basis for operation assessment and risk warning. The location of the area Flowmeter is shown in Figure. 1.

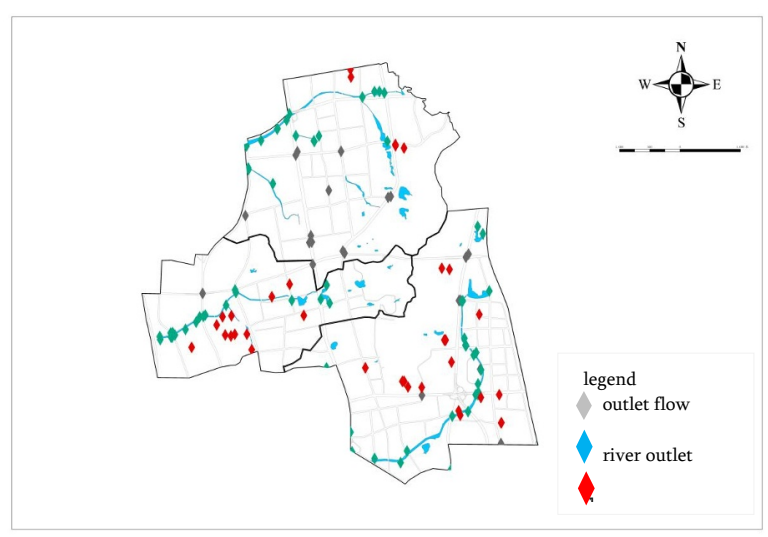

Figure 1. Regional flow monitoring point map

\section{Analysis of outlet flow to diagnose pipe network problems}

The pipe network in the area is a rainwater and sewage diversion pipe network. Therefore, there should be no flow in the rainwater pipe network during the dry season. If the rainwater pipe network detects the water flow in the dry season, there may be three situations. Firstly, the sewage pipe is mixed, which lets the sewage enter the rainwater pipe network. Secondly, the human malicious smuggling causes the sewage to enter the rainwater pipe network to form a pulse in a short time. Thirdly, the rainwater pipe network has infiltration problems, hence the Seawater or river water is poured into the pipe network or groundwater is infiltrated into the pipe network. The following analysis of the possible problems of the pipe network bases on the monitoring data. 


\subsection{Regular domestic sewage mixed into the rainwater pipe network}

If the flow data in the pipe network shows a strong periodicity and is similar with the time distribution with the discharge of domestic sewage, it can be considered that there is a problem of mixed sewage in the pipe network. If the volatility of sewage retains the regularity of domestic water drainage, there are two possibilities for this phenomenon: first, the domestic sewage comes from only one area; second, the domestic sewage comes from multiple areas, and these areas are far from the monitoring point. The distance is almost the same, otherwise there will be a change in the law of the waveform caused by the waveform superposition.

From June 1, 2018 to June 30, 2018, there is a problem of regular domestic sewage mixing into rainwater pipe network in the pipe network system corresponding to four outlets, and the point of regular domestic sewage mixed into the pipe network is shown in Table 1.

Table 1. List of regular domestic sewage mixed into the pipe network

\begin{tabular}{cccc}
\hline $\begin{array}{c}\text { Outfall } \\
\text { number }\end{array}$ & $\begin{array}{c}\text { Equipment } \\
\text { number }\end{array}$ & $\begin{array}{c}\text { Max flow } \\
(\mathbf{L} / \mathbf{s})\end{array}$ & $\begin{array}{c}\text { Average } \\
\text { daily flow } \\
\left(\mathbf{m}^{\mathbf{3}} / \mathbf{d}\right)\end{array}$ \\
\hline 1 & 17620148 & 1020 & 4.101 \\
2 & 18620122 & 1130 & 14.741 \\
3 & 18620126 & 1400 & 17.814 \\
4 & 18610117 & 0.63 & 1.229 \\
\hline
\end{tabular}

In outfall 1, in the absence of rainfall, the domestic sewage continuously flows into the stream. The flow is concentrated in the daytime. The peak appears in a certain regularity, and the peak appears once every 2-3 days. During the monitoring period, the liquid level is relatively stable, fluctuating around $0.045 \mathrm{~m}$, and the highest daily flow during the dry season is $13.664 \mathrm{~m} 3 / \mathrm{d}$. At outfall 3, the peak shows a certain regularity. Two peaks appear around 9:00 and 15:00 respectively every day, and the highest daily flow in the dry season is $88.953 \mathrm{~m} 3 / \mathrm{d}$. The curves of the outfall 2 and 4 are similar, and the peaks of the liquid level appear more consistently and appear as multiple peaks. The minute data of the above outfalls is shown in Figure 2.
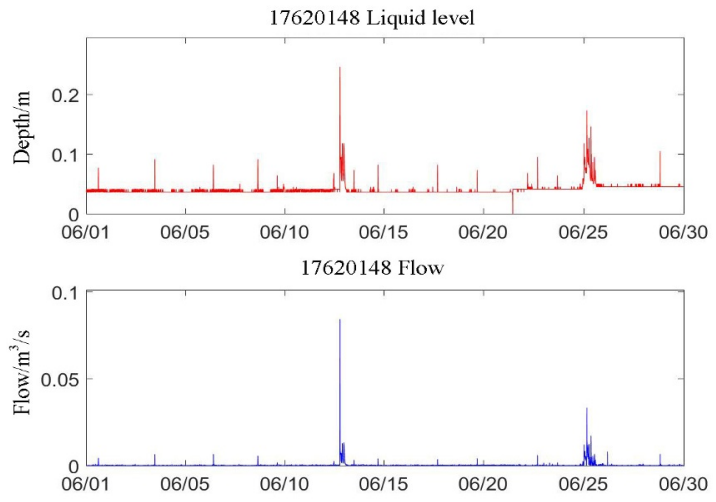

(a)
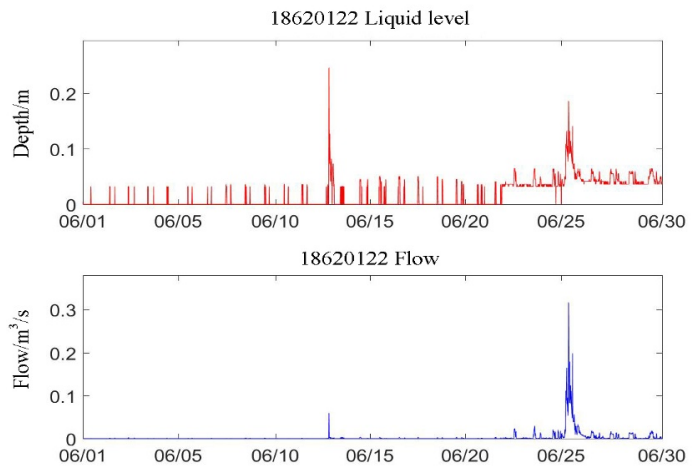

(b)

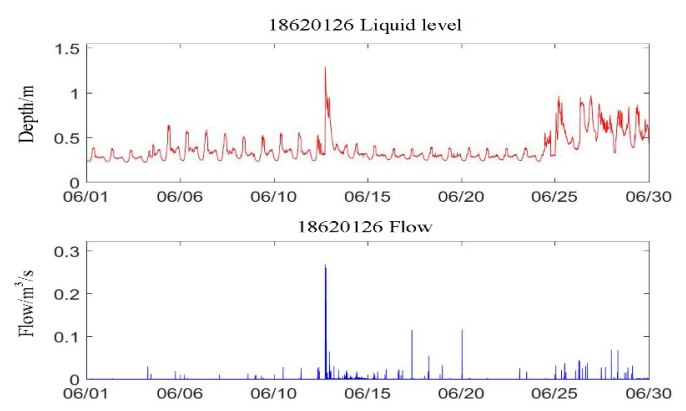

(c)
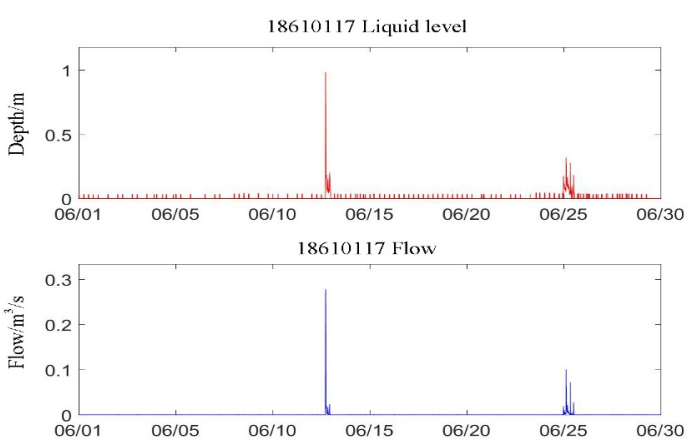

(d)

Figure 2. Data diagram of regular domestic sewage mixed into Pipe Network

\subsection{Irregular sewage or infiltration into rainwater pipe network}

According to the monitoring data, if the flow data of the rainwater pipe network outlet or node during the nonrainfall period is greater than 0 , then it can be judged that there is a problem with the pipe network, and sewage or infiltration water enters the rainwater pipe network. Among them, if the periodicity of the flow is not significant, then the source of water in the pipe network cannot be determined. This phenomenon indicates that there is a problem that the pipe network has irregular sewage or infiltration water entering into the pipe network. The problem of irregular sewage or infiltration water entering into the rainwater pipe network requires further investigation to determine the cause. After that, we can take corresponding measures and finally solve the problem.

After analysis, from June 1st to June 30th, there are 7 sets of equipment corresponding to the 7 outlets related 
to the pipe network system, there are irregular sewage or infiltration water into the rainwater pipe network, as shown in Table 2.

Table 2. List of irregular sewage or infiltration water entering the pipe network

\begin{tabular}{cccc}
\hline $\begin{array}{c}\text { Outfall } \\
\text { number }\end{array}$ & $\begin{array}{c}\text { Equipment } \\
\text { number }\end{array}$ & $\begin{array}{c}\text { Max flow } \\
(\mathbf{L} / \mathbf{s})\end{array}$ & $\begin{array}{c}\text { Average } \\
\text { daily flow } \\
\left(\mathbf{m}^{\mathbf{3} / \mathbf{d})}\right.\end{array}$ \\
\hline 1 & 17610128 & 0.491 & 1.28 \\
2 & 17610133 & 1.751 & 33.07 \\
3 & 18620136 & 2150 & 784.75 \\
4 & 18620140 & 190 & 34.91 \\
5 & 18620156 & 500 & 3375.53 \\
6 & 18620176 & 1630 & 47.58 \\
7 & 17620131 & 97.14 & 581.46 \\
\hline
\end{tabular}

Among them, there are large sewage inflows and serious mixing in outfall 3,5 , and 7 . Part of the outfalls flow data is shown in Figure 3.
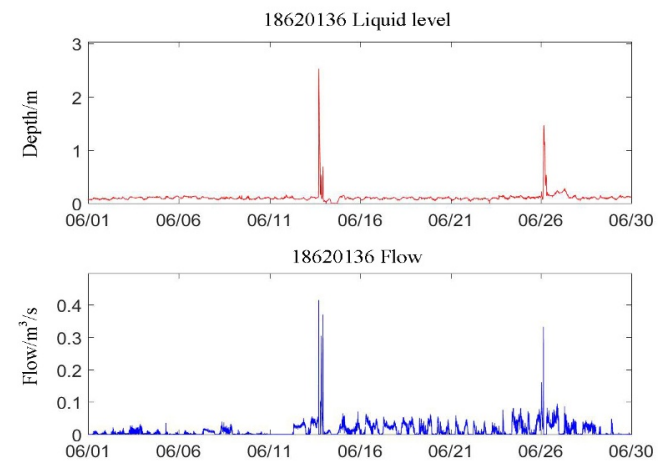

(a)
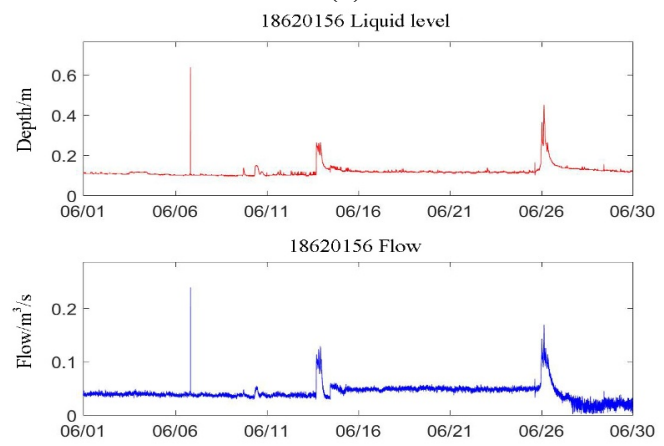

(b)

Figure 3. Part data diagram of irregular domestic sewage mixed into Pipe Network

\subsection{Sewage sneaked into the rainwater pipe network for a short time}

If the flow data in the pipe network exhibits a strong pulse law and the periodicity in the time distribution is poor, it can be considered that there is a problem of short-term stealing in the pipe network. The problem of pipe network smuggling is usually difficult to find in general manual inspection, but it is harmful to pipe network and water body. Therefore, with the support of intelligent online equipment, it should be further investigated and disposed.

After analysis, there are a total of six outlets corresponding to the pipe network in the monitoring period. There is a problem of short-term sneak peek in the rainwater pipe network. The short-time smuggling of the rainwater pipe network is shown in Table 3.

Table 3. List of short-time sneak points in the rainwater pipe network

\begin{tabular}{cccc}
\hline $\begin{array}{c}\text { Outfall } \\
\text { number }\end{array}$ & $\begin{array}{c}\text { Equipment } \\
\text { number }\end{array}$ & $\begin{array}{c}\text { Max flow } \\
(\mathbf{L} / \mathbf{s})\end{array}$ & $\begin{array}{c}\text { Average } \\
\text { daily flow } \\
\left(\mathbf{m}^{\mathbf{3} / \mathbf{d})}\right.\end{array}$ \\
\hline 1 & 17620169 & 640 & 1.60 \\
2 & 18620174 & 540 & 19.40 \\
3 & 18620137 & 940 & 34.13 \\
4 & 18620138 & 1100 & 44.31 \\
5 & 18620357 & 254.88 & 28.39 \\
6 & 18620367 & 758.70 & 47.92 \\
\hline
\end{tabular}

The transient flow of the above outfalls is so large, showing a strong pulse. Part monitoring data of sewage smuggling into the rainwater pipe network is shown in figure 4 .
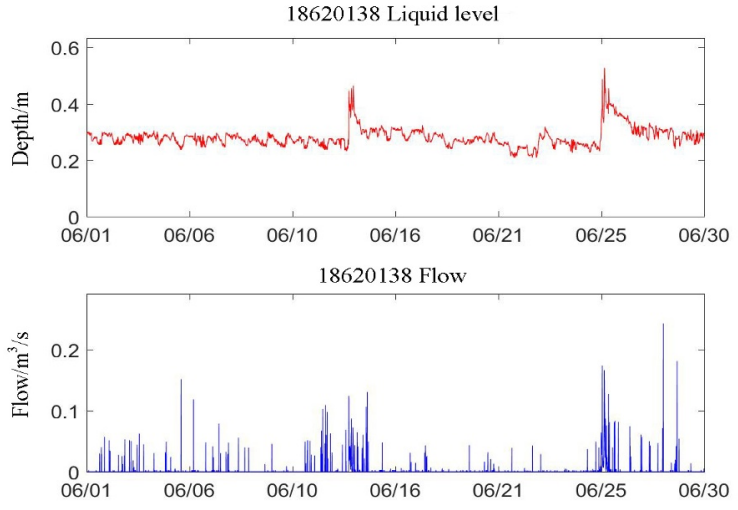

(a)
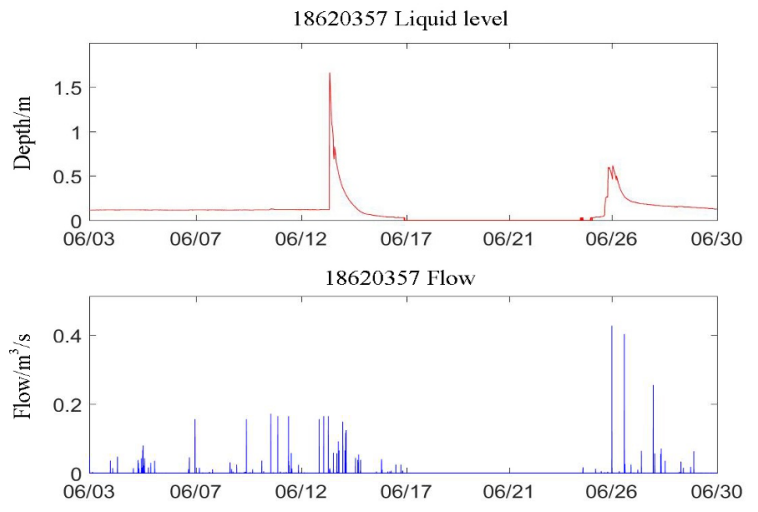

(b)

Figure 4. Part monitoring data of sewage smuggling into the rainwater pipe network

\subsection{Tidal backwater}

According to the online monitoring platform, a tidal roofing phenomenon was found in one of the outfalls. This outfall is located at the sea. The platform exports the non-rainfall daily liquid level data from July 12 to 21 . The tidal backwater curve of the discharge is shown in Figure 5. 


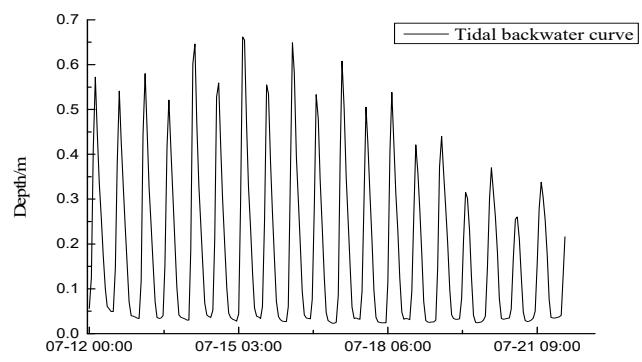

Figure 5. Tidal tidal backwater curve of one coastal outfall

Due to the location closed to sea and the low level of the inspection well, this outfall is affected by the tidal backwater of the seawater, and the liquid level fluctuation curve is consistent with the tidal time curve of the China Maritime Service Network. The highest liquid level of the discharge port is as high as $0.662 \mathrm{~m}$ and the average liquid level is $0.181 \mathrm{~m}$.

\section{Conclusion}

The results of monitoring data analysis show that there are 17 outfalls with mixed connection of rain and sewage. Among them, 4 outlets have regular sewage discharge into the rainwater pipe network, 7 outlets have irregular sewage discharge into the rain pipe network, 6 outlets have the phenomenon of sewage smuggling. It is recommended to check the mix of sewage outlets and rainwater pipes in the direction of the pipe network. There is a sea tidal backwater phenomenon in one of the coastal drainage outfalls. It is necessary to predict the tide level in advance during rainfall, prepare emergency plans, and strengthen flood control and drainage management. With the help of the Internet of things big data technology and automatic analysis algorithm, we can intelligently analyze the operation status of the pipe network, discover the pipe network problems in time, and provide scientific and effective decision-making recommendations for the operation and management of the drainage system.

\section{Acknowledgment}

The National Natural Science Foundation of China (51478230)

\section{References}

1. Lee J H. Determination of Optimal Water Quality Monitoring Points in Sewer Systems using Entropy Theory. Entropy, 15, 16 (2013)

2. Saegrov S, Schilling W. Care-s: Computer Aided Rehabilitation of Sewer and Storm Water Networks. American Society of Civil Engineers, 61, 15 (2005)

3. Watson J P, Phillips C A, Hart W E, et al. Sensor Placement in Municipal Water Networks. Journal of Water Resources Planning \& Management, 131, 7 (2005)
4. Jiménez-Buendía M, Ruiz-Peñalver L, Vera-Repullo $\mathrm{J}$ A, et al. Development and assessment of a network of water meters and rain gauges for determining the water balance. New SCADA monitoring software. Agricultural Water Management, 151, 10 (2015)

5. Matthew M. D. V, Dicht S, Leitão J P. floodX: urban flash flood experiments monitored with conventional and alternative sensors. Earth System Science Data, 9, 17 (2017)

6. Guo $\mathrm{Y}$, Holton $\mathrm{C}$, Luo $\mathrm{H}$, et al. Identification of Alternative Vapor Intrusion Pathways Using Controlled Pressure Testing, Soil Gas Monitoring, and Screening Model Calculations. Environmental Science \& Technology, 49 (2015)

7. Wang D, Runping L I, Huang G. Progresses in Study of Pipeline Robot. Machine Tool \& Hydraulics, (2008)

8. Shao L, Wang Y, Guo B, et al. A review over state of the art of in-pipe robot International Conference on Mechatronics and Automation. IEEE, 6 (2015) 